\title{
Efeitos da arginina na reparação cicatricial da parede abdominal em ratos Wistar.
}

\section{Effects of arginine on abdominal wall wound healing in Wistar rats.}

\author{
Filipe Carlos Caron ${ }^{1}{ }^{1}$; João Carlos Domingues Repka²; Viviane Gomes Milgioransa ${ }^{1}$; Jorge Rufino Ribas Timi, TCBC-PR ${ }^{1}$
}

\author{
R E S U M O
}

\begin{abstract}
Objetivo: avaliar os efeitos da arginina na cicatrização da parede abdominal de ratos Wistar. Métodos: vinte ratos Wistar foram submetidos à laparotomia e separados em dois grupos (arginina e controle), que receberam tratamento diário por via intraperitoneal com arginina (300mg/kg/dia) e solução tampão fosfato em dose equivalente ao peso, respectivamente, durante cinco dias. No sétimo dia pós-operatório, coletaram-se amostras de sangue e da cicatriz da parede abdominal de ambos os grupos. Avaliaram-se o nível sérico de nitratos e nitritos, a evolução cicatricial pelas dosagens de hidroxiprolina tecidual, formação de tecido de granulação, determinação da porcentagem de colágeno maduro e imaturo, densidade de miofibroblastos e angiogênese. Empregaram-se os testes de ANOVA e t de Student com p=0,05 para as comparações entre os grupos. Resultados: não ocorreram diferenças significantes entre os grupos estudados para dosagens de nitratos e nitritos $(p=0,9903)$, hidroxiprolina tecidual $(p=0,1315)$ e densidade de miofibroblastos $(p=0,0511)$. 0 grupo arginina apresentou maior densidade microvascular $(p=0,0008)$, maior porcentagem de colágeno tipo I $(p=0,0064)$ e melhora na formação do tecido de granulação, com melhores índices de proliferação angiofibroblástica $(p=0,0007)$ e re-epitelização das bordas $(p=0,0074)$. Conclusão: na avaliação cicatricial da parede abdominal de ratos Wistar sob tratamento com arginina, não houve alteração do nível sérico de nitratos e nitritos, da deposição de colágeno total e da densidade de miofibroblastos. Verificaram-se aumento da maturação de colágeno do tipo I, da densidade microvascular e melhora na formação do tecido de granulação cicatricial pelas melhores re-epitelização de bordas e proliferação angiofibroblástica.
\end{abstract}

Descritores: Arginina. Cicatrização. Hidroxiprolina. Colágeno Tipo I. Parede Abdominal. Ratos Wistar.

\section{INTRODUÇÃO}

A cicatrização de feridas é um processo dinâmico que envolve os fenômenos de homeostasia, inflamação, proliferação celular e remodelamento tecidual'. Volumes significantes de recursos têm sido destinados ao tratamento de complicações pós-operatórias causadas pelo retardo em algum dos fenômenos cicatriciais ou pela não cicatrização, o que motivou grandes investimentos em pesquisas voltadas à melhor compreensão da fisiopatologia dessas complicações. Além disso, graças aos avanços em metabologia cirúrgica, nutrição e bioquímica, outras pesquisas buscaram investigar a síntese de substâncias capazes de melhorar ou abreviar o tempo do processo cicatricial, como o estudo experimental que demonstrou que a suplementação com arginina na dieta de ratos aumentava a força tênsil e a deposição de colágeno em tecido lesionado².
A arginina, um aminoácido semiessencial, desempenha papel fundamental no metabolismo de diversos componentes do organismo, propiciando numerosos e peculiares efeitos farmacológicos ${ }^{3}$. É recrutada nas fases agudas e crônicas da cicatrização e é comprovadamente precursora, entre outras moléculas, do óxido nítrico $(\mathrm{ON})$, que coopera na angiogênese e no processo cicatricial como um todo. A angiogênese, por sua vez, é um fenômeno cicatricial da fase proliferativa que coopera para que células e fatores de crescimento possam dar prosseguimento à fase da remodelação, com a maturação de colágenos e aumento da força tênsil cicatricial ${ }^{4}$.

O objetivo deste estudo é investigar o efeito da administração intraperitoneal de arginina na cicatrização da parede abdominal de ratos Wistar, considerando como indicadores a síntese e maturação de colágeno, a formação de tecido de granulação e as densidades teciduais microvascular e de miofibroblastos. 


\section{MÉTODOS}

Utilizaram-se 20 ratos Wistar (Rattus norvegicus albinus, Rodentia mammalia) com idades entre 180 e 210 dias e peso de $408,4 \pm 40,1 \mathrm{~g}$ mantidos a uma temperatura controlada entre $19^{\circ} \mathrm{C}$ e $23^{\circ} \mathrm{C}$ e ciclos de iluminação automaticamente regulados a cada 12 horas. Os ratos foram separados em dois grupos com pesos estatisticamente similares $(p=0,2452)$, e colocados em caixas de polipropileno com cepilho (substituídos a cada 24 horas), com no máximo quatro ratos em cada caixa. Todos os animais recebiam ração específica para a espécie e água ad libitum. Permaneceram nessas condições pelos sete dias que antecederam os experimentos e também durante estes, que foram executados em um único ciclo de atividades.

Observaram-se os Princípios Éticos na Experimentação Animal do Colégio Brasileiro de Experimentação Animal (COBEA-2000) e o projeto foi aprovado pelo Comitê de Ética em Pesquisa em Animais (CEPA) do Hospital e Maternidade Angelina Caron, Campina Grande do Sul, PR, conforme protocolo no 012/11-CEPA/HAC.
Os procedimentos cirúrgicos foram executados em ambiente devidamente sanitizado e climatizado. Para a indução anestésica, realizou-se sedação por inalação de isoflurano (Isothane-Baxter®) em circuito fechado. Utilizaram-se os anestésicos cloridrato de cetamina (Ketamin-Cristalia $®$ ) na dose de $100 \mathrm{mg} / \mathrm{kg}$ de peso corporal, aferido por meio de balança analítica (Coleman® SK280251), associado a $10 \mathrm{mg} / \mathrm{kg}$ de cloridrato de xilasina (XilazinSyntec $($ ) utilizando duas seringas descartáveis de $1 \mathrm{ml}$ (BD-Plastiplak $($ ) e agulhas hipodérmicas (BDPlastiplak $®)$ para cada rato.

Após confirmação da indução anestésica, pela perda do reflexo interdigital, procedia-se à tricotomia ampla do abdome, fixação do animal em decúbito dorsal com fita adesiva na prancha cirúrgica, degermação da área tricotomizada com álcooliodado e colocação de campos cirúrgicos fenestrados esterilizados. Por meio de laparotomia mediana de $3 \mathrm{~cm}$ de extensão, um único médico-cirurgião executava a abertura da pele e tecido muscular. A seguir, suturava-se a ferida cirúrgica em dois planos (músculo-aponeurótico e pele), com pontos contínuos utilizando fio Mononylon 3.0 (Figura 1).

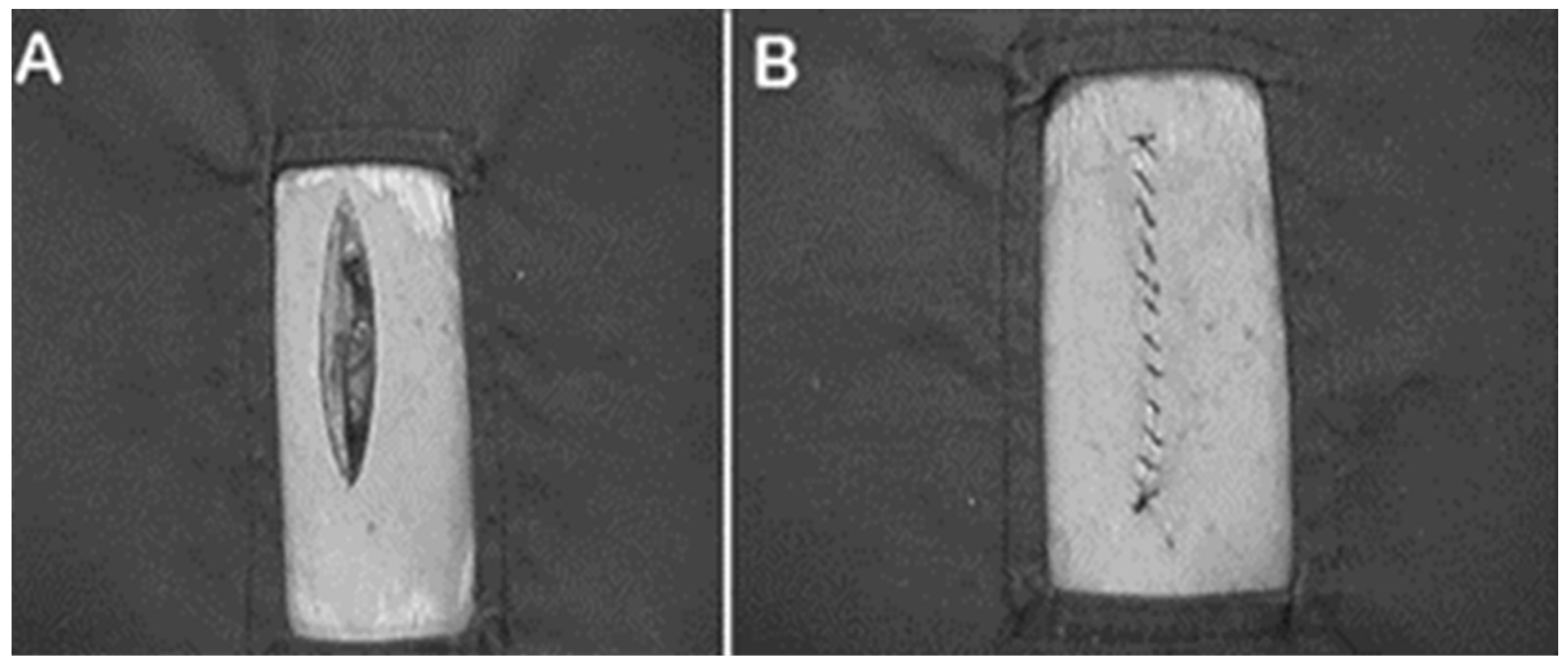

Figura 1. Etapas do procedimento cirúrgico: laparotomia mediana com abertura da pele e tecido muscular e acesso à cavidade peritoneal (A); ferida cirúrgica suturada em dois planos: músculo-aponeurótico e cutâneo (B). 
Após o fechamento, limpava-se a ferida cirúrgica com solução salina e aplicava-se novamente álcool-iodado. Administrava-se dipirona por via oral, na dose de $20 \mathrm{mg} / \mathrm{kg}$ e $10 \mathrm{ml}$ de solução salina por via subcutânea na região dorsal e os ratos eram mantidos sob aquecimento até a recuperação anestésica. A seguir eram recolocados em caixas devidamente identificadas e, durante as 24 horas seguintes, eram mantidos com ração e água ad libitum até o sétimo dia pós-operatório.

Os tratamentos consistiram em injeções intraperitoneais na dose de $300 \mathrm{mg}$ de arginina/kg/ dia para o grupo arginina e dose equivalente de solução tampão fosfato (PBS) para o grupo controle, aplicadas com os ratos sedados por inalação de isoflurano uma vez ao dia, por cinco dias. O início do tratamento (primeira dose) foi no pós-operatório imediato, com os ratos ainda sedados.

Para o grupo arginina, foi utilizada solução de L-Arginina (Merck® artigo K21051142) a $20 \%$ em PBS pH 7,4, esterilizada por filtração em membranas de 20m (Millipore-SCWP304F0®). Para o grupo controle, foi utilizada solução PBS $\mathrm{pH} 7,4$, esterilizada por filtração em membranas MF (SCWP304F0 Millipore®). Em ambos os casos, a solução PBS foi aliquotada em frascos esterilizados e mantidos a $4 \pm 2^{\circ} \mathrm{C}$.

No sétimo dia pós-operatório, os ratos foram submetidos à sedação por inalação de halotano (Tanohalo-Cristáliaß) em circuito fechado, anestesiados por injeção intramuscular com cloridrato de cetamina na dose de $100 \mathrm{mg} / \mathrm{kg}$ e fixados em pranchetas cirúrgicas. A seguir realizou-se punção cardíaca com coleta de $8 \mathrm{ml}$ a $10 \mathrm{ml}$ de sangue, volume correspondente a uma punção exanguinativa e indutora de parada cardiorrespiratória. Ainda sob plano anestésico e com evidência de morte, procedeuse a ressecção da ferida operatória contendo camada músculo-aponeurótica e pele. As amostras coletadas foram estendidas em papel filtro, lavadas em solução PBS pH 7,4 e separadas em dois fragmentos.
Um dos fragmentos, destinado às dosagens de hidroxiprolina, foi imerso em solução PBS pH 7,4 e mantido em freezer a $-80^{\circ} \mathrm{C}$ até o processamento laboratorial. O outro fragmento, destinado às avaliações histopatológicas, foi imerso em frasco identificado contendo formalina tamponada.

A dosagem de hidroxiprolina tecidual foi analisada pelo método espectrofotocolorimétrico ${ }^{5,6}$, que avalia o conteúdo total de hidroxiprolina em amostras de tecido, fornecendo uma medida da deposição de colágeno total em micrograma $(\mu \mathrm{g})$ por miligrama (mg) de tecido úmido. As amostras foram avaliadas em duplicatas e, para validação dos resultados, as leituras espectrofotométricas a $560 \mathrm{~nm}$ foram tabuladas e validadas estatisticamente.

Para as avaliações microscópicas, as amostras foram fixadas em formalina tamponada e, após a retirada dos fios de sutura, submetidas ao processamento histológico automatizado, que consistia nas fases de desidratação, diafanização e emblocamento. A seguir, eram efetuadas secções perpendiculares ao maior eixo da sutura, em triplicatas, com micrótomo a $4 \mathrm{~mm}$ de espessura, as quais eram fixadas em lâminas para serem coradas conforme a avaliação a ser feita, seguindo os itens a seguir.

Para avaliação da porcentagem de colágeno dos tipos I e III, os cortes histológicos foram submetidos à coloração de Picrosirius-Red-F3BA ${ }^{7}$ e analisados por meio de microscópio óptico em aumento de 400 vezes, utilizando-se fonte de luz polarizada. As imagens eram captadas por câmera fotográfica, transmitidas a um monitor colorido e digitalizadas.

Realizou-se a análise histométrica das imagens mediante o aplicativo Image Pro-Plus versão 4.5 para Windows para a identificação do tipo de colágeno, baseada em cores. As cores vermelho, amarelo e laranja correspondiam a colágeno tipo I, enquanto que os tons de verde correspondiam ao colágeno tipo III. O resultado foi expresso em área percentual de colágeno tipo I e tipo III em cada local do corte histológico. 
Foram procedidas três leituras de campos diferentes em cada lâmina, as quais foram tabuladas e validadas estatisticamente.

Para avaliação da formação de tecido de granulação, os cortes histológicos corados com hematoxilina-eosina (HE) de Harris foram avaliados por três patologistas independentes, sendo considerada em cada leitura a intensidade da reação inflamatória cicatricial mediante avaliação dos seguintes fenômenos: formação de crosta fibrinoleucocitária, pela observação de depósitos de fibrina e células sanguíneas na superfície da ferida; re-epitelização das bordas, dedicando-se especial atenção ao avanço do epitélio em torno da ferida; e proliferação angiofibroblástica, mediante avaliação morfológica de neovascularização (angiogênese). A esses achados foram atribuídos graus 0, 1 e 2 para a ausência de reação, reação em grau discreto e em grau moderado, respectivamente . $^{2}$

Do material emblocado em parafina foram obtidos cortes histológicos de $4 \mathrm{~mm}$ de espessura estendidos em lâminas de vidro e imunomarcados com anticorpos anti-CD34, o que permitiu a quantificação da densidade microvascular cicatricial. O antígeno CD34 é uma proteína transmembrana encontrada na superfície de células endoteliais, sendo expresso difusamente nos microvasos cicatriciais, e que atua na ligação com receptores específicos de adesão celular. Além disso, seu nível de expressão pode se correlacionar à qualidade do processo cicatricial ${ }^{9}$.

Foi empregado o método da imunoperoxidase com o uso da técnica da estreptavidina-biotina, com controles positivo e negativo, utilizando o reagente Biotin anti-CD34 antibody clone QBEnd/10® (Dako Corporation, Glostrup, Dinamarca) diluído a 1:350, seguindo a especificação do fabricante ${ }^{10}$. As reações foram consideradas positivas quando se detectou reação marrom, excluindo-se as prováveis áreas de coloração de fundo com padrão de reação nuclear, sendo que qualquer célula endotelial (ou grupo de células endoteliais) de coloração marrom claramente separada de outros elementos imunocorados, independentemente do tamanho, era considerada um microvaso. A análise foi realizada por histometria computadorizada e os resultados foram expressados em densidade tecidual de miocrovasos em uma área de $7.578,94 \mathrm{~mm}^{2}$.

Do material emblocado em parafina foram obtidos cortes de $3 \mathrm{~mm}$ de espessura, os quais foram estendidos em lâminas de vidro e imunomarcados com anticorpos monoclonais anti-a-actina muscular lisa para a identificação de miofibroblastos. Foi empregado o método da imunoperoxidase ${ }^{11,12}$, com o uso da técnica da estreptavidina-biotina, com controles positivo e negativo, utilizando o reagente Biotin anti-aSMA antibody clone PJC $10 \AA$ (Dako Corporation, Glostrup Dinamarca) diluído a 1:400, seguindo a especificação do fabricante. As reações foram consideradas positivas quando se detectou reação marrom, excluindo-se as prováveis áreas de coloração de fundo, com padrão de reação nuclear. A análise foi realizada por histometria computadorizada e os resultados foram expressados em densidade tecidual de miofibroblastos em uma área de $7.812,26 \mathrm{~m}^{2}$.

A dosagem de nitratos foi feita em amostras de plasma obtido de sangue coletado por punção cardíaca. Foram avaliadas quatro alíquotas de uma mesma amostra (tetraplicatas) e empregou-se o reagente de Griess (sulfanilamida a 2\%, N-1-naftil etilenodiamina a 0,2\% e ácido ortofosfórico) para as dosagens. A mistura amostra/reagente de Griess foi incubada por $5 \mathrm{~min}$ a $37^{\circ} \mathrm{C}$ e, a seguir, realizou-se a leitura da densidade ótica em espectrofotômetro a $520 \mathrm{~nm}^{13}$. Simultaneamente ao teste ANOVA para validação dos resultados, foi preparada uma curva de calibração com padrão de nitritos nas concentrações de 40, 80, 120, 160 e 200 mmol/l. Após a validação do método, as densidades óticas médias foram interpoladas por regressão linear na curva de calibração e, assim, obtidos os resultados em mmol/l. 
Para validação estatística das análises, os resultados de cada uma das medições de uma mesma amostra foram comparados pelo teste $t$ de Student (dosagens de hidroxiprolina) ou ANOVA (demais variáveis). Não foram encontradas diferenças significativas ( $p>0,05)$ entre as leituras em nenhuma das variáveis analisadas neste estudo, o que permitiu validar esses resultados e proceder às comparações entre as médias dos grupos calculando-se média aritmética de cada amostra e a média do grupo com desvio padrão. Os resultados foram expressos como média \pm desvio padrão e empregaram-se os testes $t$ de Student e ANOVA com $p=0,05$ para as comparações entre os grupos utilizando o software GraphPad InStat.

\section{RESULTADOS}

Ao serem comparadas estatisticamente pelo teste $t$ de Student, as médias das dosagens de hidroxiprolina dos grupos arginina e controle, apresentaram diferença não significativa $(0,0304 \pm 0,0073$ versus $0,0250 \pm 0,0081 ; p=0,1355)$. A figura 2 descreve a comparação entre as médias dos grupos controle e arginina para as porcentagens de colágeno I $(p=0,0064)$ e colágeno III $(p=0,0274)$, com valores maiores para o grupo arginina e controle, respectivamente.

A tabela 1 demonstra as comparações entre as médias dos grupos controle e arginina para re-epitelização de bordas $(p=0,0074)$ e proliferação angiofibroblástica ( $p=0,0007)$.

Quanto à avaliação histométrica da densidade microvascular cicatricial (Figura 3), foram observados valores significativamente maiores para o grupo arginina $(282,06 \pm 99,12$ no grupo controle versus 446,33 $\pm 81,59$ no grupo arginina; $p=0,0008$ ). Da mesma forma, a densidade tecidual de miofibroblastos foi maior no grupo arginina, mas sem significância estatística $(367,49 \pm 68,34$ no grupo controle versus $429,28 \pm 63,78$ no grupo arginina; $p=0,0511)$. As médias da dosagem de nitrato e nitrito séricos foram de $1,35 \pm 0,26 \mathrm{mmol} / / \mathrm{l}$ e $1,35 \pm 0,23 \mathrm{mmol} / /$ para os grupos controle e arginina, respectivamente, sem diferença estatisticamente significativa $(p=0,9903)$ (Figura 4).

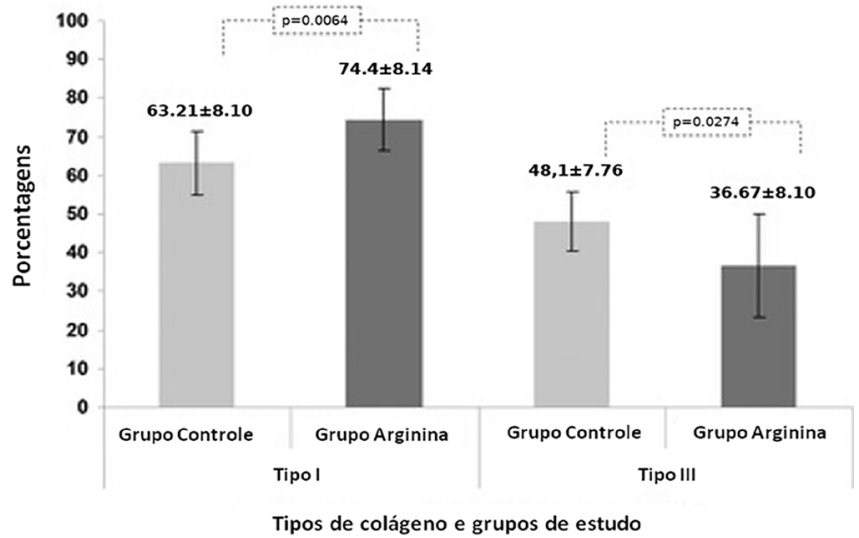

Figura 2. Comparação entra as médias das porcentagens de colágenos dos tipos I e III entre os grupos avaliados.

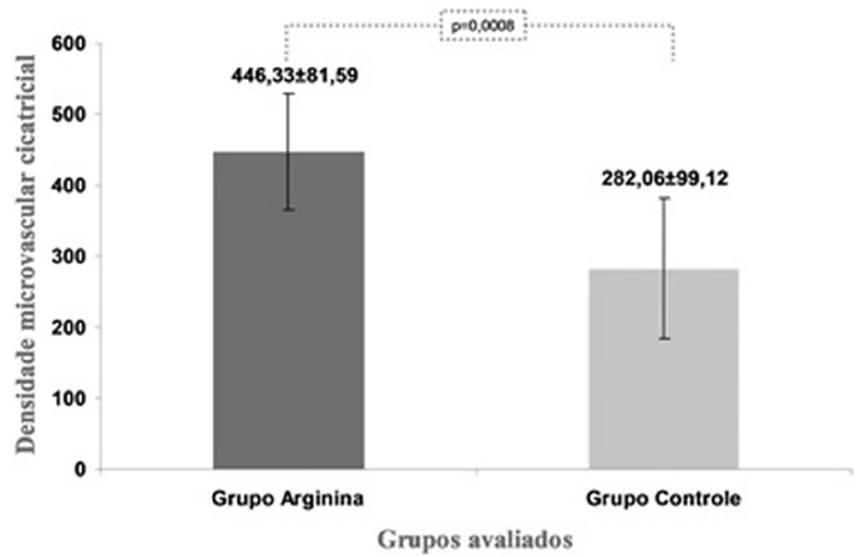

Figura 3. Comparação entra as médias das densidades microvasculares entre os grupos avaliados.

Tabela 1. Comparação entre as médias dos grupos controle e arginina na formação de tecido de granulação conforme os critérios de formação de crosta fibinoleucocitária, re-epitelização de bordas e proliferação angiofibroblástica.

\begin{tabular}{lccc}
\hline \multicolumn{1}{c}{ Grupos } & Crosta fibrinoleucocitária & Re-epitelização de bordas & Proliferação angiofibroblástica \\
\hline Controle & 1 & $1,4 \pm 0,52$ & $1,37 \pm 0,46$ \\
Arginina & 1 & $1,93 \pm 0,21$ & $1,97 \pm 0,11$ \\
$\mathrm{p}$ & $\mathrm{n} / \mathrm{a}^{*}$ & 0,0074 & 0,0007 \\
\hline
\end{tabular}

* n/a: não adequado para cálculo estatístico; valores expressos em média desvio padrão. 


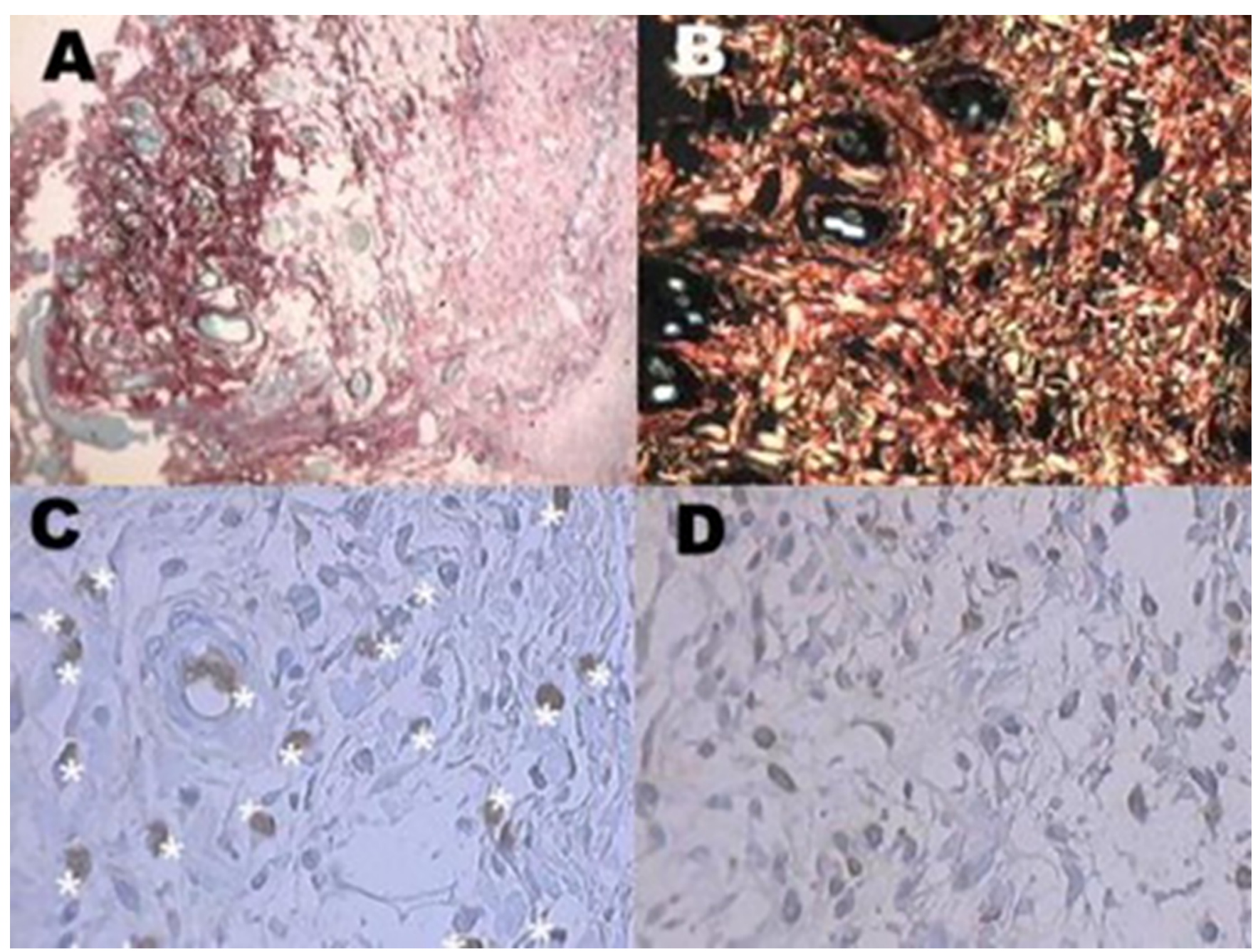

Figura 4. Avaliações histológicas: A e B) quantificação de colágenos tipo / e lll por histometria computadorizada pela coloração de picro-sirius. No detalhe "A" microscopia ótica e no detalhe " $B$ " após polarização sendo que as cores vermelho, amarelo e laranja correspondem ao colágeno tipo I, enquanto que os tons de verde correspondem ao colágeno tipo III; C) avaliação da densidade microvascular cicatricial pelo método da imunoperoxidase com anticorpo monoclonal anti-CD34, tendo sido consideradas positivas, como um microvaso, a reação marrom em qualquer célula endotelial ou grupo de células endoteliais, claramente separada de outros elementos imunocorados; D) avaliação da densidade tecidual de miofibroblastos pelo método da imunoperoxidase com anticorpos monoclonais anti-a-actina muscular lisa para a identificação de miofibroblastos, tendo sido consideradas positivas, como um miofibroblasto, a reação marrom em qualquer célula.

\section{DISCUSSÃO}

Estudos prévios demonstraram a importância do ON na cicatriação e na angiogênese de feridas ${ }^{14}$ Além disso, um modelo desafiante de estudo de cicatrização em ratos Zucker (diabéticos e obesos) evidenciou melhora do processo cicatricial com o emprego de fórmula hiperprotêica enriquecida com arginina, além de prolina ${ }^{15}$. Considerando esses achados, o presente estudo visou comparar os processos cicatriciais na parede abdominal de ratos, conforme parâmetros bioquímicos e histopatológicos, após tratamento com arginina + solução PBS (grupo arginina) ou solução PBS (grupo controle), injetadas por via intraperitoneal.

Estudos experimentais em ratos foram executados com o objetivo de verificar os efeitos da arginina na cicatrização pós-operatória em intestinos e pele, em queimaduras, incorporação de material sintético na parede abdominal, com diferentes doses e vias de administração, como oral, subcutânea e intraperitoneal ${ }^{16-20}$. 
Um deles concluiu que, no trauma, torna-se essencial a suplementação com arginina, já que seu uso em humanos está relacionado ao aumento da cicatrização de feridas, a um efeito positivo no sistema imune e à redução de dias de internação. Isso ocorre através da promoção da proliferação de linfócitos e fibroblastos, que serve como um substrato intracelular para produção de óxido nítrico em macrófagos para melhorar a atividade bactericida ${ }^{21}$.

O tratamento com arginina, com a mesma dose utilizada no presente estudo, mas administrada por via subcutânea, demonstrou, no processo cicatricial de retalho cutâneo em ratos, indução de angiogênese e aumento da deposição de colágeno total ${ }^{17}$.

No presente estudo, os efeitos do tratamento com arginina na ferida cirúrgica foram avaliados bioquimicamente pela determinação do teor de hidroxiprolina tecidual, que representa a deposição total de colágeno, e histologicamente pela quantificação de colágenos I e III e pela avaliação da formação de tecido de granulação, da angiogênese e da densidade tecidual de miofibroblastos.

A avaliação da quantidade de colágeno total, indicada pela hidroxiprolina tecidual, permite uma análise valiosa, porém parcial, do processo cicatricial, pois devem ser também considerados os diferentes tipos de colágeno, os quais apresentam diferenças na composição química e na forma de associação entre suas moléculas, interferindo na resistência cicatricial. Concomitantemente à deposição e maturação do colágeno em uma cicatriz, ocorre o ganho progressivo de força tênsil, que pode ir aumentando por até dois anos após o inicio do processo de cicatrização .

A hidroprolina pode ser sintetizada a partir da L-arginina por duas vias metabólicas: a via da arginase e a via da ornitina-aminotransferase, as quais produzem a maior quantidade tecidual de prolina. No presente estudo, contrapondo-se aos resultados de Shukla et al. ${ }^{18}$, não houve diferença significante entre as médias de hidroxiprolina teciduais nos grupos arginina e controle, apesar de aumento numérico.
Além da taxa absoluta do colágeno, representada pelo conteúdo em hidroxiprolina, a forma de disposição de suas fibras também é responsável pela resistência tecidual. Entre as 19 isoformas de colágeno identificadas até o presente, o colágeno tipo I é o mais frequente e predominante em ossos e tendões, sendo considerado colágeno maduro. É também o mais importante, pois é responsável não apenas pela manutenção da integridade da maioria dos tecidos, em função das suas propriedades mecânicas ${ }^{22}$, mas também por sua participação ativa na funcionalidade dos tecidos, em função de sua interação com as células presentes na matriz extracelular. O tipo III, por sua vez, é mais comumente encontrado em tecidos moles, como vasos sanguíneos, derme e fáscia. Já o tecido de granulação expressa 30\% a 40\% de colágeno do tipo III, sendo considerado colágeno imaturo.

No presente estudo, observou-se maior média na porcentagem de colágeno tipo I no grupo arginina quando comparado ao grupo controle $(p=0,0064)$, o que pode ser explicado quando se avaliam os resultados da quantificação da densidade microvascular cicatricial, a qual demonstrou aumento significante também no grupo tratado pela arginina $(p=0,0008)$.

Os mecanismos da cicatrização ocorrem em uma sequência de três fases: inflamatória, proliferativa ou de formação de tecido de granulação ao sétimo dia, com maior estímulo angiogênico e síntese de colágeno, e de remodelação cicatricial pela deposição e maturação de colágeno, e, por consequência, de maturação da cicatriz.

A formação do tecido de granulação tem início com a infiltração de macrófagos, que produzem e liberam mediadores químicos, os quais intensificam a migração e a ativação de fibroblastos, explicando assim a proliferação angiofibroblástica mais intensa observada no grupo tratado com arginina no presente estudo. 
Os fibroblastos são os principais componentes do tecido de granulação e as principais células da fase proliferativa; porém, precisam ser ativados para sair de seu estado de quiescência. A liberação do fator de transformação de crescimento beta (tumor growth factor beta, TGF-B) estimula os fibroblastos a produzirem colágeno e a transformarem-se em miofibroblastos, que promovem a contração da ferida. No presente estudo, as densidades teciduais de miofibroblastos não diferiram entre o grupos arginina e controle $(p=0,0511)$, apesar de ter ocorrido diferença numérica. Estudo experimental em ratos que investigou a densidade de miofibroblastos na cicatrização de feridas pelo mesmo método ora empregado concluiu que o metronidazol, aplicado de forma tópica nas feridas com cicatrização por segunda intenção, não interfere na contração da ferida e atrasa o aparecimento dos miofibroblastos ${ }^{23}$. Por outro lado, um recente estudo experimental concluiu que a administração tópica de solução de metronidazol em feridas de pele com cicatrização por segunda intenção foi capaz de melhorar a diferenciação de fibroblastos, fato que pode ser utilizado em favor do processo de cicatrização de feridas ${ }^{24}$.

A importância dos miofibroblastos no processo cicatricial decorre também pelo fato de que o processo de contração da ferida alcança a sua eficiência máxima durante a fixação dos fibroblastos e seu amadurecimento fenotípico para células produtoras de colágeno. Isso é devido à mudança de fenótipo dos fibroblastos das margens da ferida para miofibroblastos, que são células intermediárias entre musculares lisas e fibroblastos. Apesar de seu mecanismo contrátil estar ainda por ser esclarecido, essas células são encontradas alinhadas ao redor de depósitos da nova matriz extracelular, fazendo uniões célula a célula e gerando força de tensão.

Após a influência dos fatores de crescimento, os fibroblastos são ativados e migram das margens da ferida para o seu centro, o que permite inferir sobre os efeitos da arginina na melhor re-epitelização das bordas no presente estudo. Esse processo é denominado de fibroplasia e, para a sua eficiência, é necessária a ocorrência em paralelo da formação de novos vasos sanguíneos, ou seja, é necessária a neovascularização da região ${ }^{25,26}$.

No presente estudo, o grupo arginina demonstrou densidade microvascular tecidual significativamente maior do que o grupo controle $(p=0,0008)$. Esse resultado pode ser explicado pelo fato de que são reconhecidas duas vias de degradação direta da arginina. Uma delas é mediada pela enzima arginase, que a transforma em ornitina e ureia, enquanto que, na outra, a arginina é catalisada pela enzima óxido nítrico-sintase e tem como produto o ON, um potente ativador do fator vasodilatador associado ao endotélio vascular, que é responsável pela angiogênese ${ }^{27}$.

Um estudo experimental mostrou que a L-arginina melhora a função cardíaca e reduz o tamanho do infarto em ratos com infarto agudo do miocárdio. O possível mecanismo está relacionado à dupla função de promover angiogênese e arteriogênese, além da regulação da expressão do colágeno $^{28}$.

Pode-se citar também o fato de que o ON é um metabólito que atravessa as membranas celulares com extrema facilidade, o que faz dele um mensageiro intra e intercelular que está envolvido em diferentes respostas fisiológicas e patológicas durante a cicatrização de feridas ${ }^{29,30}$. Devido ao curto tempo de vida do ON (cerca de 3 a 9 segundos), a sua dosagem direta é impraticável. Considerando que a sua metabolização gera nitratos e nitritos, os quais são estáveis e permitem suas dosagens em fluidos biológicos, como líquido cefaloraquidiano, urina, fluidos cicatriciais e plasma, essas determinações são consideradas indicadores do metabolismo da arginina. 
No entanto, tais medidas não representam a formação equimolar de ON, pois ocorre também formação não enzimática ${ }^{31}$.

No presente estudo, as dosagens de nitratos e nitritos séricos nos grupos arginina e controle não demonstraram diferença significante $(p=0,9903)$. Independente da espécie, o mecanismo de ação toxicológica do nitrito é semelhante. O nitrito oxida o $\mathrm{Fe}^{2+}$ da hemoglobina, transformando-a em metahemoglobina, a qual não possui capacidade de transportar $\mathrm{O} \quad \mathrm{O}_{2}$, causando anoxia tissular. Há relatos de morte de animais com $80 \%$ a $90 \%$ da hemoglobina oxidada $^{32}$. Empregou-se a dosagem de nitratos e nitritos para avaliar se a dose administrada de arginina poderia alterar o nível sérico de nitratos e nitritos, sendo, portanto, um indicador de possível efeito tóxico, caso se evidenciasse nível maior do que o grupo controle.

O presente estudo contribui com algumas questões importantes e promissoras com relação à cicatrização e ao uso da arginina. Partiu-se da possibilidade de que o ON, um catabólito da arginina com efeito angiogênico, pudesse melhorar a capacidade de síntese, deposição e maturação de colágeno, com consequente melhora da cicatrização. Observaram-se resultados promissores em relação à melhora da densidade microvascular tecidual, maturação de colágeno e do tecido de granulação, com perspectivas para futuros estudos em organismos com comprometimento cicatricial, como aqueles em uso crônico de corticoterapia ou com comprometimento vascular, transplantados e idosos, entre outros.

\title{
A B S T R A C T
}

\begin{abstract}
Objective: to evaluate the effects of arginine on abdominal wall healing in rats. Methods: we submitted 20 Wistar rats to laparotomy and divided them into two groups, arginine and control, which then received, respectively, daily intraperitoneal treatment with arginine $(300 \mathrm{mg} / \mathrm{kg} / \mathrm{day})$ and weight-equivalent phosphate buffered solution, during five days. On the seventh postoperative day, we collected blood and scar wall samples from both groups. We evaluated serum nitrate and nitrite levels, wound evolution by tissue hydroxyproline dosages, granulation tissue formation, percentage of mature and immature collagen, myofibroblast density and angiogenesis. We used the ANOVA and the Student's $t$ tests with $p=0.05$ for comparisons between groups. Results: there were no significant differences between the groups studied for nitrate and nitrite $(p=0.9903)$, tissue hydroxyproline $(p=0.1315)$ and myofibroblast density $(p=0.0511)$. The arginine group presented higher microvascular density $(p=0.0008)$, higher percentage of type I collagen $(p=0.0064)$ and improved granulation tissue formation, with better angiofibroblastic proliferation rates $(p=0.0007)$ and wound edge reepithelization $(p=0.0074)$. Conclusion: in the abdominal wall healing evaluation of Wistar rats under arginine treatment, there was no change in serum nitrate and nitrite levels, total collagen deposition and myofibroblast density. There was an increase in type I collagen maturation, microvascular density and improvement in scar granulation tissue formation by better edge reepithelization and angiofibroblastic proliferation.
\end{abstract}

Keywords: Arginine. Wound Healing. Hydroxyproline. Collagen Type I. Abdominal Wall. Rats, Wistar.

\section{REFERÊNCIAS}

1. Mandelbaum SH, Di Santis EP, Mandelbaum MHSA. Cicatrização: conceitos atuais e recursos auxiliares - Parte I. An Bras Dermatol. 2003;78(4):393-410.

2. Campos ACL, Borges-Branco A, Groth AK. Cicatrização de feridas. ABCD Arq Bras Cir Dig. 2007;20(1):51-8.

3. Seifter E, Rettura G, Barbul A, Levenson SM. Arginine: an essential amino acid for injured rats. Surgery. 1978;84(2):224-30.
4. Witte MB, Barbul A. General principles of wound healing. Surg Clin North Am. 1997;77(3):509-28.

5. Dietz UA, Torres OJM, Insfrán GM, Nassif PAN, Hirt ALA, Repka JCD, et al. Estudo da taxa de hidroxiprolina tecidual nos diversos segmentos do canal alimentar do cão pela técnica fotocolorimétrica utilizando o reativo de Ehrlich. Acta Cir Bras. 1995;10(3):128-34.

6. Dietz UA, Araújo AC, Czeczko NG, Lemos R, Araújo $U$, Inácio $C M$, et al. [Terminolateral esophagojejunostomy after gastrectomy with the biofragmentable anastomosis ring in the dog model]. Zentralbl Chir. 2005;130(3):274-9. German. 
7. Junqueira LC, Cossermelli W, Brentani R. Differential staining of collagens type I, II and III by Sirius Red and polarization microscopy. Arch Histol Jpn. 1978;41(3):267-74

8. Stevens A, Lowe J. Respostas teciduais ao dano. In: Stevens A, Lowe J, editores. Patologia. $2^{\text {a }}$ ed. São Paulo: Manole; 2000. p. 35-50.

9. Molgaard HV, Spurr NK, Greaves MF. The hemopoietic stem cell antigen, CD34, is encoded by a gene located on chromosome 1. Leukemia. 1989;3(11):773-6.

10. Hsu SM, Raine L, Fanger $H$. Use of avidin-biotinperoxidase complex $(A B C)$ in immunoperoxidase techniques: a comparison between $A B C$ and unlabeled antibody (PAP) procedures. J Histochem Cytochem. 1981;29(4):577-80.

11. McCaffrey TA, Du B, Consigli S, Szabo P, Bray PJ, Hartner L, et al. Genomic instability in the type II TGF-beta1 receptor gene in atherosclerotic and restenotic vascular cells. J Clin Invest. 1997;100(9):2182-8.

12. Lorena $D$, Uchio $K$, Costa $A M$, Desmoulière $A$. Normal scarring: importance of myofibroblasts. Wound Repair Regen. 2002;10(2):86-92.

13. Tatsch E, Bochi GV, Pereira RS, Kober H, Oliveira JR, Moresco RN. Influência dos anticoagulantes e da temperatura de armazenamento sobre os níveis sanguíneos de nitrito. J Bras Patol Med Lab. 2011;47(2):147-50.

14. Bonnefoy M, Coulon L, Bienvenu J, Boisson RC, Rys $\mathrm{L}$. Implication of cytokines in the aggravation of malnutrition and hypercatabolism in elderly patients with severe pressure sores. Age Ageing. 1995;24(1):37-42.

15. Raynaud-Simon A, Belabed L, Le Naour G, Marc J, Capron F, Cynober L, et al. Arginine plus proline supplementation elicits metabolic adaptation that favors wound healing in diabetic rats. Am J Physiol Regul Integr Comp Physiol. 2012;303(10):R1053-R61.

16. Corrêa-Neto MP, Campos AC, Borges-Branco A, Matias JE. Efeito da suplementação dietética de arginina na cicatrização das anastomoses colônicas em ratos. ABCD Arq Bras Cir Dig. 2009;22(1):7-14.
17. Guimarães MV, Moreira GH, Rocha LP, Nicoluzzi JE, Franco de Souza CJ, Repka JC. L-arginine action in cutaneous flap evolution under nicotine exposure in rats. Rev Col Bras Cir. 2013;40(1):49-54.

18. Shukla A, Rasik AM, Shankar R. Nitric oxide inhibits wounds collagen synthesis. Mol Cell Biochem. 1999;200(1-2):27-33.

19. Chen J, Wollman $Y$, Chernichovsky $T$, laina $A$, Sofer $M$, Matzkin $\mathrm{H}$. Effect of oral administration of highdose nitric oxide donor L-arginine in men with organic erectile dysfunction: results of a doubleblind, randomized, placebo-controlled study. BJU Int. 1999;83(3):269-73.

20. Arbos MA, Ferrando JM, Quiles MT, Vidal J, LópezCano M, Gil J, et al. Improved surgical mesh integration into the rat abdominal wall with arginine administration. Biomaterials. 2006;27(5):758-68.

21. Dos Santos PLC, Maciel DRC, Gomes S, da Silva LPE, Andrade IS, Paim VF, et al. Aspectos imunomodulatórios da suplementação com arginina em pacientes queimados. Int J Nutrology. 2018;11(S 01):S24-S327.

22. Ramachandran GN, Mitra AK. An explanation for the rare occurrence of cis peptide units in proteins and polypeptides. J Mol Biol. 1976; 107(1):85-92.

23. Trindade LC, Biondo-Simões ML, Sampaio CP, Farias $\mathrm{RE}$, Pierin RJ, Netto MC. Avaliação do uso tópico do metronidazol no processo de cicatrização de feridas: um estudo experimental. Rev Col Bras Cir. 2010;37(5):358-63.

24. Trindade LCT, Matias JEF, Sampaio CPP, Farias RE, Biondo-Simões MLP. Diferenciação de miofibroblastos em feridas após uso tópico do metronidazol: estudo experimental. Rev Col Bras Cir. 2019;46(1):e2015.

25. Knighton DR, Silver IA, Hunt TK. Regulation of wound-healing angiogenesis-effect of oxygen gradients and inspired oxygen concentration. Surgery. 1981;90(2):262-70

26. Balbino CA, Pereira LM, Curi R. Mecanismos envolvidos na cicatrização: uma revisão. Braz J Pharm Sci. 2005;41(1):27-51. 
27. Flora Filho $R$, Zilberstein B. Óxido Nítrico: $O$ simples mensageiro percorrendo a complexidade. Metabolismo, síntese e funções. Rev Assoc Med Bras. 2000;46(3):265-71.

28. Liu Y, Zhou Z, Zhu Z, Tang W, Luo L, Jian C. Oral supplementation of I-arginine improves ventricular remodeling by regulating angiogenesis and collagen synthesis in myocardial infarction rats. Am J Clin Exp Med. 2019;7(2):47-53.

29. Schwentker A, Vodovotz $Y$, Weller R, Billiar TR. Nitric oxide and wound repair: role of cytokines? Nitric Oxide. 2002;7(1):1-10.

30. Childress BB, Stechmiller JK. Role of nitric oxide in wound healing. Biol Res Nurs. 2002;4(1):5-15.

31. Rizk $M$, Witte $M B$, Barbul $A$. Nitric oxide and wound healing. World J Surg. 2004;28(3);301-6.
32. Gonzalez FH. Perfil bioquímico sanguíneo. In: Gonzalez FH. Introdução à bioquímica clínica veterinária. $2^{\mathrm{a}}$ ed. Porto Alegre: Editora da Universidade Federal do Rio Grande do Sul; 2006. p. 313-55.

Recebido em: 07/08/2019

Aceito para publicação em: 29/10/2019

Conflito de interesse: nenhum.

Fonte de financiamento: nenhuma.

\section{Endereço para correspondência:}

Filipe Carlos Caron

E-mail: fccaron@hotmail.com clauperego@bol.com.br

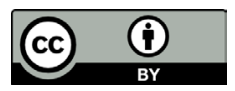

